\title{
Фотоприемные устройства на основе InGaAs
}

\author{
Н.И. Яковлева ${ }^{1}$, И.Д. Бурлаков ${ }^{1,2}$, К.О. Болтарь ${ }^{1,3}$ \\ ${ }^{1}$ ГНЦ РФ АО «НПО «Орион», Москва, 111538, Косинская ул., 9 \\ ${ }^{2}$ МТУ (МИРЭА), Москва, 119454, пр-т Вернадского, 78 \\ ${ }^{3}$ МФТИ (ГУ), МО, Долгопрудный, 141700, Институтский пер., 9 \\ тел:+7 (499) 374-9400, эл. nочта: orion@orion-ir.ru
}

DOI 10.34077/RCSP2021-145

Представлены результаты исследований матричных фотоприемных устройств (ФПУ) на основе тройных соединений InGaAs коротковолнового ИК диапазона спектра формата 320x256 элементов с шагом 30 мкм и 640х512 элементов с шагом 15 мкм, работающих в пассивном и активно-импульсном режимах реального времени [1]. Важной функциональной возможностью ФПУ формата 320х256 является функционирование в четырех режимах реального времени: пассивном $2 D$; активном $2 D$ с заданной глубиной по дальности; активно-импульсном $3 D$ (дальномерном); асинхронном бинарном для обнаружения внешних лазерных излучателей [2].

Многослойные гетероструктуры на основе InGaAs, выращенные методом MOC-гидридной эпитаксии, крайне перспективны для использования в активно-импульсных устройствах изображения, поскольку имеют чувствительность к ИК излучению с длинами волн от 0,9 до 1,7 мкм при составе $\mathrm{x}_{\mathrm{InAs}}=0,53$ мол.дол., что хорошо коррелирует с используемыми в коротковолновом ИК диапазоне длинами волн лазерного излучения: 1,06, 1,31 и 1,54 мкм. МФПУ на основе InGaAs не требуют криогенного охлаждения.

Основной задачей построения ФПУ, работающего в дальномерном режиме, являлись выбор и конструирование архитектуры матрицы фоточувствительных элементов (МФЧЭ) на основе ГЭС InGaAs c минимальными темновыми токами. Для уменьшения темновых токов до значений менее 10 фА предложена $p+/ B / n / n+$-архитектура для МФЧЭ; по своей сути она основывается на $p-i-n$ структуре, в области ОПЗ которой размещается широкозонный барьерный слой $(B)$, что позволяет блокировать ток основных носителей заряда (электронов), существенно уменьшить токи туннелирования и генерации-рекомбинации через центры ШРХ [3].

БИС считывания имеет входную ячейку, в которой одновременно реализованы два канала: высокочастотный канал, обеспечивающий работу ФПУ в режиме определения дальности и низкочастотный на основе схемы буферной инжекции для получения двухмерного изображения. Благодаря объединению в единой ячейке различных функций БИС считывания обладает следующими преимуществами: поддержка пассивных и активных режимов работы; динамическое изменение размеров считываемой области; прямое и реверсивное считывание; переключение усиления в ячейке; изменение времени накопления; переключение количества выходов; последовательный интерфейс управления; измерение дальности до объектов наблюдения; регистрация сторонних лазерных излучателей.

Исследованы параметры ФПУ на основе InGaAs в различных режимах реального времени, в том числе: в пассивном и в режиме дальномера. В пассивном режиме удельная обнаружительная способность превышает $10^{13} \mathrm{BT}^{-1} \cdot \mathrm{cm}^{\cdot} \Gamma_{L^{1 / 2}}$, дефектность менее $0,5 \%$. В режиме дальномера с максимальной кадровой частотой 2 кГц и временным разрешением 2 нс может быть достигнуто разрешение по дальности 0,6 м на расстоянии до 5 км. Экспериментально показана возможность расширения длинноволновой границы спектрального диапазона до 2,07 мкм при увеличении мольной доли $x$ в фоточувствительном слое $\operatorname{In}_{x} \mathrm{Ga}_{1-x} \mathrm{As}$ до $x=0,67$, а также расширения коротковолновой границы спектрального диапазона в видимый диапазон за счет утоньшения подложки InP.

\section{Лumepamypa}

[1] Болтарь, К.О., Чинарева, И.В., Лопухин, А.А., Яковлева, Н.И. Матричные планарные и мезаструктуры на основе гетероэпитаксиальных слоев InGaAs // Прикладная физика. - 2013. - №5. - C. 10-15.

[2] Бурлаков, И.Д., Кузнецов, П.А., Мощев, И.С., Болтарь, К.О., Яковлева, Н.И. Матричный фотоприемный модуль на основе гетероструктуры InGaAs/InP для формирователей 3Dизображений в коротковолновом ИК-диапазоне // Успехи прикладной физики. - 2017. - том 5. - № 4. - С.383-392.

[3] Яковлева, Н.И., Болтарь, К.О., Седнев, М.В., Никонов, А.В. Исследование свойств фотоприемных устройств на основе гетероэпитаксиальных структур InGaAs, предназначенных для формирователей $3 D$-изображений // Успехи прикладной физики. 2016. том 4. № 5.С. 465-470. 